\title{
Experiences of HIV/AIDS home-based caregivers in Vhembe district of the Limpopo Province
}

\author{
NS Mashau, M Cur \\ Lecturer: Department of Public Health, University of Venda \\ M Davhana-Maselesele, D Phil \\ Faculty of Agriculture, Science and Technology, North West University (Mafikeng Campus)
}

\section{Key words}

Burnout, Home-based caregivers, Stigma, Stress.

\section{Correspondence address}

School of Health Sciences

University of Venda

Thohoyandou, 0950

Tel:(015)962-8622

Fax: 0865470576

E-mail:ntsieni.mashau@univen.ac.za

\section{Abstract: Curatlonis 32 (4): 40-47}

The purpose of this study was to explore and describe the experiences of HIV and AIDS home-based caregivers in the Vhembe district of Limpopo Province. A qualitative research design which was exploratory, descriptive and contextual was executed with a sample of purposively selected participants who provided home-based care to people living with HIV and AIDS in the Vhembe district of Limpopo Province. Data saturation occurred after in-depth interviews with fifteen participants. In-depth individual interviews and field notes were also used during data collection.

The findings reveal that HIV/AIDS home-based caregivers express pain and despair when caring for HIV/AIDS patients. The theme was supported by the following categories and subcategories: problems related to stigma when caring for patients at their homes; stress, burnout, frustration and feelings of helplessness when caring for patients. Recommendations that are described focus on building a working relationship between the home-based caregivers, community and the family.

\section{Introduction and background}

The growing HIV and AIDS pandemic continues to make a serious impact on all countries throughout the world. Globally, countries have responded to the HIV and AIDS pandemic by investing millions of dollars to help fight the disease, but the impact of HIV and AIDS is even greater in developing countries of Sub-Saharan Africa, including South Africa (Department of Health, 2001: 2).

One of the goals of South Africa in its HIV and AIDS Strategic Plan for 20072011 is to provide adequate treatment, care and support services in communities through the development of appro- priate home-based care implementation guidelines (Department of Health, 2007: 22). In its National guidelines, the South African government has indicated that the HIV and AIDS epidemic is making it difficult for the hospitals to cope with the increasing number of patients because hospitals are overcrowded owing to a disproportionately inadequate number of medical, nursing and allied health professionals. It was resolved that, with the current situation persisting, home-based care will provide a back-up for people who need extended care and it was clearly stated in the national guidelines that home-based care should not be taken as "cheap care or second class care" for those who cannot afford hospital care (Depart- 
Lack of resources such as home-kits within home-based care programmes in South Africa is reported to be yet another major problem. It is further reported that the majority of HIV and AIDS home-based caregivers are using extremely limited resources and work under extreme pressure. Generally, HIV and AIDS home-based caregivers are not trained nurses; they are volunteering community members who are dedicated to helping other people in the community (SebanyoniMothlasedi, 2003:33).

In his speech about HIV and AIDS, the former President of South Africa, Mr Thabo Mbeki, stressed the importance of caring for people living with HIV and AIDS (Maister, 2001: 36). HIV and AIDS home-based caregivers, therefore, have a very important role to play in ameliorating the condition of HIV and AIDS sufferers through caring.

\section{Statement of the problem}

Health-care services in South Africa are unable to cope with the increasing number of HIV and AIDS patients, and therefore patients are discharged earlier from hospitals to be cared for in the familiar home environment. Some hospitals in South Africa are reported to have eventually decreased the patient's average stay from 14 days to just 3.5 days whilst referring patients to home-based care organizations (Leake, 2009: 1). In South Africa HIV and AIDS home-based care is almost always provided by community volunteers who are unemployed. They carry out basic care to people living with HIV and AIDS (PLWHA) who are sick at home. Some of the PLWHA cannot help themselves in performing tasks such as bathing, going to the toilet, feeding and cooking because they are suffering from debilitating HIV and AIDS-related diseases. Home-based caregivers often carry out household chores, in addition to the basic care that they provide (Leake, 2009:2; SebanyoniMothlasedi, 2003:33).

A comparative study of South Africa and Uganda showed that home-based care (HBC) programmes in South Africa are inadequately developed as compared to those in Uganda. It was found that many HBC programmes in South Africa still reflect a response of crisis management and were found to be unsustainable because they rely on volunteers from the affected communities to carry out the caregiving activities in patients at their homes (Akintola, 2004:3). Given the background that home-based care (HBC) is becoming a dominant programme in HIV and AIDS treatment and support in South Africa, the need to understand the experiences of HIV and AIDS home-based caregivers in providing care to patients at their homes is indispensable in order to work on its sustainability. One central research question was used to give direction to the study: What are the experiences of HIV and AIDS homebased caregivers in the Vhembe district of the Limpopo Province?

\section{Objectives}

The objectives of this study were to:

- $\quad$ explore and describe the experiences of HIV and AIDS homebased caregivers in Vhembe district of Limpopo Province; and to

- describe recommendations which would facilitate support for HIV and AIDS home-based caregivers.

\section{Definition of concepts}

Burnout is defined by Uys and Cameron (2003: 28) as the tendency of a person to become despondent and develop a negative self-image.

Burnout in this study refers to physical and emotional exhaustion suffered by HIV and AIDS home-based caregivers which may lead to reduced energy for continuing to work in the provision of home-based care.

Debriefing in this study, refers to a process through which HIV and AIDS home-based caregivers can be able to verbalise their fears, pain and problems to a professional psychologist who will in turn help them to get treatment.

Home-based caregivers are defined as families, professionals, community health workers, volunteers and church groups who provide health care to people in their home environment (Department of health, 2001: 4). In this study home-based caregivers refer to individuals/lay people or groups of people in the community who are responsible for providing care to HIV and AIDS patients at their homes.

Home-based care is defined as the provision of health care services by for$\mathrm{mal}$ and informal caregivers in the home in order to promote, restore and maintain a person's maximum level of comfort, function and health including care towards a dignified death (Department of Health, 2001: 1). In this study it refers to the method of using trained volunteers to provide health care to individuals at their homes with the purpose of assisting the patients to meet their needs in order to promote good health.

\section{Research design and method}

A qualitative, explorative, descriptive and contextual research design used to explore and describe the experiences of HIV and AIDS home-based caregivers for this study (Creswell, 2009:175).

The population of this study comprises of all HIV and AIDS home-based caregivers in the Vhembe district of the Limpopo province. A non-probability, purposive sampling method was used because it enabled the researcher to consciously select voluntary HIV and AIDS home-based caregivers who had been trained in home-based care, had worked for a year as a home-based caregiver and were still working with home-based patients in the community. HIV and AIDS home-based caregivers were the most appropriate participants to share their experiences regarding caring for HIV and AIDS patients (Burns \& Grove, 2007: 241; Creswell, 2009: 175).

Fifteen home-based caregivers were selected from different Home-based care (HBC) organisations within Vhembe district of Limpopo Province. Fourteen of the participants were females and only one was a male. Their ages ranged between 27 and 52 years.

They had been working as volunteers in home-based care for more than one year and most of them had no other employment except one who was also a hairdresser. Ten participants were single parents living with their children and some were staying with their parents. The remaining five participants were married. 


\begin{tabular}{|c|c|c|}
\hline THEME & CATEGORY & SUBCATEGORY \\
\hline \multirow[t]{3}{*}{$\begin{array}{l}\text { 1.1 HIV and AIDS home-based } \\
\text { caregivers expressed pain and despair } \\
\text { when caring for HIV and AIDS patients. }\end{array}$} & 1.1.1 Problems related to stigma. & $\begin{array}{l}\text { Reluctance on the part of patients } \\
\text { to readily welcome HIV and AIDS } \\
\text { home-based caregivers. } \\
\text { Late disclosure of HIV and AIDS } \\
\text { status by patients. } \\
\text { Poor support of home-based } \\
\text { caregivers by the families of } \\
\text { PLWHA. } \\
\text { Lack of knowledge by family } \\
\text { members regarding caring for } \\
\text { their loved ones. }\end{array}$ \\
\hline & 1.1.2 Stress and burnout. & $\begin{array}{l}\text { - } \quad \text { Suffering and death of patients } \\
\text { Fear of contracting the HIV } \\
\text { virus. }\end{array}$ \\
\hline & $\begin{array}{l}\text { 1.1.3 Frustration and feelings of helpless- } \\
\text { ness. }\end{array}$ & $\begin{array}{l}\text { - } \quad \text { Lack of basic resources } \\
\text { - Walking long distances. }\end{array}$ \\
\hline
\end{tabular}

In-depth individual interviews were used to get more information on the experiences of HIV and AIDS homebased caregivers (De Vos, Strydom, Fouche \& Delport, 2007: 298; Morse, Swanson \& Kuzel, 2001:83). During the interviews, HIV and AIDS home-based caregivers were able to express their experiences freely without restrictions. The researcher and the participants were involved in interviews in which they were co-participants (Henning, van Rensburg \& Smit, 2004:74). The interviews took about 45 to 60 minutes each. The broad question that was asked enabled the researcher to gain a better understanding of the experiences of HIV and AIDS home-based caregivers. Probing questions were asked to allow for deeper and more thoughtful responses from the participants (Rubin \& Rubin, 2005:159).

Field notes were used to record the non-verbal cues that were observed during the interview. This was done in the presence of participants after the purpose was explained to them (Neuman, 2000:364). An audiotape recorder was used to record the interviews and the data was later transcribed verbatim for analysis purposes (Henning, Van Rensburg \& Smit, 2004: 75).

Data sets were analysed using Tesch's eight steps of open coding in which raw data was organised into one theme, categories and subcategories (Cresswell, 2009: 186).

\section{Measures to ensure trustworthiness}

To ensure that the findings of this study are a true reflection of human experience, the model of Lincoln and Guba (De Vos, Strydom, Fouche \& Delport, 2007: 345) was used. Four criteria for establishing trustworthiness were used, namely: truth value (credibility), applicability (transferability), consistency (dependability), and neutrality (conformability). The strategy of credibility was used to ensure that the findings of the study reflect the experiences of HIV and AIDS home-based caregivers. The following methods were used to confirm credibility:

- Prolonged engagement: The researcher was engaged in a prolonged interaction with the HIV and AIDS home-based caregivers during data collection.

- Member checking: Follow-up interviews were conducted with some participants for validation of data that was already gathered.

- $\quad$ Peer review: Several meetings were held with the supervisor who is experienced in research methods. Study findings were presented ibefore a team of senior researchers.

The strategy of transferability was used to ensure applicability. Transferability was enhanced by giving a dense description of the experiences of HIV and AIDS home-based caregivers.

The strategy of dependability was used to ensure consistency which was enhanced by coding and re-coding of data by an independent coder who has a doctoral qualification, with experience in qualitative research methods.

The strategy of conformability was used to ensure neutrality. Transcriptions, audiotapes and field notes were made available to supervisors to confirm the findings.

\section{Ethical measures}

In order to do what was right and good without violating the rights of the participants, the following ethical measures were considered: ethical clearance was obtained from the University's Ethics Committee and the Limpopo Provincial Ethical Research Committee. The following ethical measures were considered throughout the process of the research to protect the rights of participants (Creswell, 2009:89, LoBiondoWood \& Haber, 2002: 273): permission 
to conduct research was sought from HBC organisations and participants. The researcher developed an informed consent for participants to sign before engaging in the research to ensure that participants' rights were protected throughout the process of the study. Participants were informed that participation in this study was voluntary and they should feel free to withdraw from participation at any time if they felt like doing so. Codes instead of names were used to ensure anonymity of participants and raw data was not exposed to anyone except to the supervisors of the study. Participants were assured that the information they provided would not be used against them.

\section{Discussion of the findings}

The table that follows gives a summary of the findings of this research according to themes, categories and subcategories.

\section{Theme 1: HIV and AIDS home- based caregivers expressed pain and despair when providing care to HIV and AIDS patients at their homes.}

During the data collection process with HIV and AIDS home-based caregivers, participants expressed that they experienced pain and despair while providing home-based care to patients suffering from HIV and AIDS. These are discussed under the following categories: problems related to stigma; stress and burnout; frustration and feelings of helplessness. The discussion that follows gives a description of each category, its subcategory, direct quotations and literature control.

\section{Problems related to stigma}

HIV and AIDS home-based caregivers indicated that they experienced many problems that were related to stigma when providing care to HIV and AIDS patients at their homes.

\section{- Reluctance on the part of patients to welcome HIV and AIDS home-based caregivers.}

Discussions with HIV and AIDS homebased caregivers revealed that when they visited patients at their homes for the first time, they were not freely welcomed by patients, but as time went on, with subsequent visits, patients began to accept and welcome them. Reluctance to be welcomed by patients was also expressed in terms of fear of being seen with an $\mathrm{HBC}$ by friends and neighbours.

Participants expressed statements such as: "... Other patients after disclosing their status to us, they want us to visit them, but you will find that they are afraid of their neighbours. They believe that our visit will make the neighbours aware of their HIV and AIDS status. You will find that this person is not completely free, but...(pause) with us the person will show happiness and even verbalise that our visit makes him/her happy. But this person will tell you that don't come on such a day..... (pause) because maybe the neighbour will be around and we are not on good terms therefore you must come in the absence of the neighbour."

According to Baker, Williams, Juma and Mahendra (2005:1), HIV and AIDS is also associated with discrimination by community members, and people living with HIV and AIDS find it difficult to just welcome and trust a voluntary home-based caregiver on his/her first visit. It is believed that during initial visits by the home-based caregiver, it is the time when some patients are trying to come to terms with the diagnosis of HIV and AIDS.

\section{- $\quad$ Late disclosure of their HIV and AIDS status by patients}

Participants reported that late disclosure of their status by patients affected the process of caring that they should provide. This is how a participant expressed it: "These people due to fear of disclosing their status, they end up not taking treatment for a long period after disclosing their status, it might be due to the fact that they start disclosing their status when they are unable to do anything, or when they are bedridden."

Participants indicated that they believed that the reason for late disclosure was fear of the stigma that is attached to HIV and AIDS disease. Unfortunately it delays the process of receiving care and support and therefore their condition becomes worse before they could be assisted.

According to Lindsey, Hirschfeld, Tlou and Ncube (2003:498), it has been found that stigma often prevents people from accessing available health care services because they are afraid that people will know about their HIV -positive status, and therefore continuous care and support from HIV and AIDS home-based caregivers is delayed. This finding is also supported by Baker, et al. (2005:1). It is explained that stigma and discrimination discourage people infected with HIV and AIDS from seeking the services they need because it may lead to the revelation of their HIV status to their families, colleagues and community.

\section{- $\quad$ Poor support of home-based} caregivers by the families of PLWHA

It was evident from the interviews with HIV and AIDS home-based caregivers that if the family was not taking care of their sick relative then the whole burden of caring would rest upon them. HIV and AIDS home-based caregivers reported that in some families they found that patients were not cared for by family members. It was expressed by a participant as follows: "Sometimes family members distance themselves from taking care of the patient and do not accept the patient. You will find that in the whole family there is no one who is taking into consideration the sick family member. We once had a problem where the mother could not take care of her daughter and did not love her. She even provided her with separate eating utensils (plate and mug) because she did not want anything to do with HIV and AIDS, saying that she will infect them before she dies, she did not even come to see her."

Peltzer, Skinner, Mfecane, Shisana, Nqeketo and Mosala (2005:38) reported that women who are suffering from HIV and AIDS disease indicate that their partners and other family members do not support and take care of them physically and emotionally. Therefore it means that voluntary home-based caregivers alone have to carry the burden of providing total care and support to HIV and AIDS patients.

In this study, participants revealed that in some families they were at least accepted by relatives when the patients' condition started to deteriorate. One participant said: "Some families start by not accepting us, but as the condi- 
tion worsens and when they see that there is nothing that they can do, then they accept us so that we can help them in caring for their relative. They think that we will assist them and relieve them of their burden. "It would appear there was an element of opportunism on the part of some family members. Mostly it was only that they required an extra, willing pair of hands more than anything.

\section{- $\quad$ Lack of knowledge by family members regarding care of their loved ones}

Findings from this study revealed that lack of knowledge by family members hampered caring for their loved ones as it exacerbated stigma and discriminatory practices. Adebayo, Irinoye, Oladoyini and Fakande (2004: 52) identify lack of knowledge about HIV and AIDS as the main reason for family members' not taking care of their loved ones. In this study participants indicated that family members were afraid of taking care of the patient because of lack of knowledge about HIV and AIDS. One participant said: "They do not know how this disease is transmitted, the truth is that people lack knowledge, yes they lack knowledge."

The findings from this study revealed lack of knowledge about the mode of spread of HIV by relatives and family members as a contributing factor to rejection and isolation, and therefore they were afraid that they might contract the disease during caring. According to Smith (2003:29), the advantages of home health care include strengthening the family unit and restoring family control. Clients recover more quickly at home than in hospitals; home care allows for easier access to loved ones and their support; home care is a less threatening and more familiar and comfortable environment which enhances care and the quality of life.

It is clear that there are many benefits to patients if they are cared for at home, but according to this study it was not always the case, as some patients were not getting help from their loved ones.

\section{- $\quad$ Stress and Burnout}

According to Uys and Cameron (2003:28), voluntary HIV and AIDS home-based caregivers carry the heaviest load for providing continuous care to patients who are suffering from HIV and AIDS at their homes because they work under difficult circumstances. It is a natural response for one to feel sad and tired when one is constantly exposed to suffering and loss when one is doing one's job, but without support it can lead to the development of stress and burnout. In this study a participant expressed the effects of stress as follows: "I was suffering emotionally for three months. I was stressed, suffered continuous headaches and had difficulty in coping with work. It came to the time where I told myself that I could not continue working as a home-based caregiver, the reason being that I could feel that I was frustrated and things were not going smoothly, as I expected."

Emotional pressure accumulated during the caring for HIV and AIDS patients by HIV and AIDS volunteers, lack of support for the voluntary HIV and AIDS caregivers where there are no resources, as well as lack of training, can contribute to causing stress which predisposes an individual to burnout (Bennet, Ross \& Sunderland, 1996:145). During the discussions with the HIV and AIDS home-based caregivers, the following factors were identified as the causes of stress and burnout:

\section{- $\quad$ Suffering and death of patients}

In this study participants expressed the stress that they feel when they witness patients dying of HIV and AIDS-related diseases. From the discussions with the HIV and AIDS home-based caregivers it was clear that during the process of providing care to patients, they became emotionally attached to patients in such a way that they would do everything in order to satisfy the needs of the patients without considering their own.

This is further supported by Phaladze (nd: 8), who also indicates that HIV and AIDS caregivers carry an immeasurable burden because when their patients suffer, they also suffer, and this suffering is characterised by feelings of helplessness and despair.

A participant expressed the emotional distress of witnessing patients in their care dying: "Emotionally we feel pain because you find that as we are pro- viding care to patients we become close and form a good relationship with the family. In the family if there is a problem with the patient, the first person that they think of is "me" the caregiver. We are the first people to be called by family members if the patient dies, they will say: "Your patient is dead...!" It means that for the arrangement of the hearse and other immediate needs, the family will be looking up to me because offrustration. Therefore I must act bravely because if I panic then we will all be uncontrollable and will not be able to make immediate arrangements effectively."

The findings in this study reveal that HIV and AIDS home-based caregivers expressed the emotional distress of having to arrange for the removal of the body after the death of a patient at home. They felt that if the relatives of the dying patient called them, it was their responsibility to show support to the family because they were taking care of the client before death.

Participants expressed that losing a patient through death was very painful because they felt that they had done their best, devoting their time and energy when caring for the patient. Therefore death was perceived as a loss to the HIV and AIDS home-based caregiver.

\section{- $\quad$ Fear of contracting HIV and AIDS}

One of the potential risks associated with caring for HIV and AIDS clients is the increased probability of contracting the disease through exposure. In care-giving there is commitment of time and effort that may be made at a high price to the self because for care giving to be complete, the caregiver believes that it has to be recognised by the cared-for person, which is very hard to establish at times (Phaladze, nd: 1).

In this study some participants expressed their fear of contracting the infection while providing care to HIV and AIDS patients at their homes.

Some participants explained that they use gloves when bathing or changing patients " position but they did not tell their patients that the reason for wearing gloves was to protect them as caregivers from getting infection from 
the patient. Participants further indicated that some patients did not feel good if the caregiver was wearing gloves. This is how the participants explained it: "Some patients do not feel free when we use gloves while caring for them, but we explain that we are protecting them from getting infection from us."

In this study some participants indicated that the gloves were too thin, to such an extent that they tore when they were bathing a patient and if a patient had sores, or if the gloves were not intact, one could get infected.

The risk of getting infected is reported to be high during the terminal stages of HIV and AIDS when the patient is bedridden. The body fluids are infected and the voluntary home-based caregiver will be dealing with these discharges (Uys \& Cameron, 2003:129). This is the time when the patient needs total basic care including bathing, changing of linen, wound dressing, feeding etc., therefore there is too much contact with body fluids and the risk of transmission of infection is high.

\section{- Frustration and feelings of helplessness}

In this study participants expressed feelings of frustration which they experienced every day when they assisted patients at their homes because of lack of basic resources and having to walk long distances to get to their patients. Participants cited poverty as a major problem that they were experiencing during the provision of homebased care. In other studies it has also been discovered that home-based caregivers in developing countries are faced with poverty in all its ugliness. HIV and AIDS home-based caregivers find it frustrating getting into households to assist with care and finding families including the patient hungry and cold, without hope of relief (Uys \& Cameron, 2003:162). The following two subcategories will be discussed in detail:

\section{- $\quad$ Lack of basic resources}

During interviews with HIV and AIDS home-based caregivers, lack of basic resources was cited as a very big problem. Participants in this study explained that when they visited patients in their homes they felt helpless and frustrated because they found patients living in extreme poverty where there was no food or even water to drink. They indicated that it became a burden which they felt that they had to carry because if there was no food, they had to make sure that the patient got something to eat before treatment was taken, as they could not give treatment on an empty stomach. In this study participants explained that they were forced by the conditions under which their patients were living to fetch water and also to buy bread for their patients.

This is how a participant expressed it: "You go to a patient and you find that the patient has antiretroviral drugs. You want to give the patient those drugs but it becomes a problem when there is no food. As home-based caregivers we know that we cannot give antiretroviral drugs on an empty stomach. ... (Pause, shaking the head) that is where you are forced to use the few cents that you have to buy a piece of bread for the patient to eat before taking treatment. It becomes better if there is PVM soft porridge."

Another participant said: "Sometimes you will find that there is no food at all for the patient to eat. In situations like these we refer the patient to the social worker. Our main problem is the shortage of food parcels because even if we have referred our patients, you find that they come back emptyhanded. Lack of food delays treatment because the patient cannot take medication on an empty stomach. Due to poverty, we even find HIV and AIDS patients and their children with no clothes. It frustrates us. We take it upon ourselves to seek donations of clothes from churches and give them to HIV and AIDS patients and their children. The majority of HIV and AIDS patients are unemployed and some are weak in such a way that they are unable to work."

Participants verbalized the emotional distress that they felt when the patient requested soft porridge from them and they promised to bring it the following day. If they did not get it, they felt embarrassed to face the patient the following day because they knew that their relationship of trust with the patient could be affected. In a study on action learning and reflection with HIV and AIDS home-based care workers in Gauteng by Pistorius (2002: 6), participants reported the guilty feelings that they experienced after a patient asked to be given money to buy fruit.

Throughout the discussions with the participants, they could not hide the pain that they felt when visiting a patient who was hungry. HIV and AIDS home-based caregivers found themselves in a dilemma because they knew that treatment must not be taken on an empty stomach, and here they were bringing treatment to a hungry patient. Participants in this study explained that they were emotionally affected when they were to provide treatment and found that the patient was hungry. These are situations that force voluntary HIV and AIDS home-based caregivers to utilise their insufficient funds to meet the needs of the patients. Participants cited lack of resources as a stumbling block for the provision of quality home-based care to HIV and AIDS patients in their familiar home environment. It is also reported that home-based care volunteers in developing countries are working under very difficult circumstances where there are poor housing facilities, lack of electricity and clean drinking water (Leake, 2009:2).

By referring patients to other structures, HIV and AIDS home-based caregivers are trying to help meet the needs of patients. During the discussions with participants it was discovered that they encountered problems when their patients needed assistance from other sectors. They explained that sometimes when they assist patients with social problems, for example, births registration for children and grants, they experienced difficulties in getting proof of residential address from traditional leaders and civic associations. One participant explained: "Our patients are expected to pay R20.00 when getting letters from the traditional leaders or civic associations. These people are poor, and they cannot afford to pay $R 20.00$. We are forced as caregivers to collect $R 2.00$ from each one of us until we get $R 20.00$, so that the patient can get assistance."

\section{- Walking long distances}

During the discussions with HIV and AIDS home-based caregivers the prob- 
lem of having to walk long distances from one patient to the other was expressed. Participants also indicated that by the time they reached the patient's home, they were already tired because in rural areas the households were scattered and some areas were mountainous. Pistorius (2002:7) reported that home-based caregivers reported exhaustion of having to walk long distances to visit patients and were not getting travelling allowance.

One participant said: "It is a huge problem for us because when we reach the patient's home we are already tired by walking long distances. How can you provide care when you are tired? And as volunteers, we feel pain ... (Pause). Presently as you can see the sun is very hot and when you reach the patient's place you are already tired because of the heat. I go out to visit patients in the morning and come back home in the afternoon and by that time you will find that it is very hot. When you get up the following morning you are still tired and you will feel reluctant to go out to visit patients."

Participants explained that they walked long distances, up to $10 \mathrm{~km}$, when visiting HIV and AIDS patients in their homes and they got tired before they could help the patient. It became worse if they found that there was no water to bath the patient and they had to go up to $3 \mathrm{~km}$ to fetch water with a 20 or 25 liter container.

\section{Recommendations to support HIV and AIDS home-based caregivers}

The following are recommendations that were described, based on the findings of the study to support HIV and AIDS home-based caregivers: Policy formulators of the Department of Health and Social Development should draw guidelines to support HIV and AIDS home-based-caregivers. The guidelines should include the following:

- Formation of support groups for HIV and AIDS home-based caregivers to promote emotional support. By forming support groups, caregivers would be able to share experiences and advice each other on how to deal with stress.

- Counseling services for HIV and AIDS home-based caregivers to be provided at clinic level by professional nurses and social workers.

- $\quad$ Food parcels for patients should be kept at clinics so that they can be accessible. This will assist patients as they will not need transport to collect food parcels from the social development offices as they will be able to walk to the nearest clinic. It would be easier for the HIV and AIDS home-based caregivers to report to the clinic for bedridden patients to be supplied with food.

- $\quad$ Traditional authorities and civic structures to work closely with HIV and AIDS home-based caregivers in all matters related to assisting PLWHA like for example, providing proof of residence to PLWHA free of charge. Priority should be given to PLWHA with regard to provision of services such as housing, water and electricity.

- The Department of Health and Social Development should make provisions in its budget to increase the monthly stipend of HIV and AIDS home-based caregivers so that they can be able to afford transport to move around when helping HIV and AIDS patients in the community.

- Government departments and

business sector should make provision for funding all income-generating projects operating under a home-based care organisation so that homebased caregivers can be financially self-sufficient.

\section{Limitations of the study}

The study was exclusively conducted in one district of Limpopo Province. Therefore, a generalisation of findings is not possible. However, there is both a possibility and a need for the research to be replicated in other districts.

\section{Conclusion}

In this study the experiences of HIV and AIDS home-based caregivers were explored, measured and qualified. HIV and AIDS home-based caregivers expressed the pain and despair that they experienced while providing homebased care to patients. The researchers discovered that the findings of this study highlighted needs of the HIV and AIDS home-based caregivers that were often not attended to because they were overwhelmingly masked and superseded by the care that should be provided to HIV and AIDS patients at their homes. It was discovered that caregivers also had a whole range of support needs that should be met.

\section{References}

ADEBAYO, BA; IRINOYE, OO; OLADOYINI, MA \& FAKANDE, I 2004: Community Home-based Care (CHB) for people living with HIV and AIDS: Example from Living Hope Care and support organisation, in Osun state, Nigeria. Africa Journal of Nursing and Midwiferv. 6(1):49-55

AKINTOLA, O 2004: Health Economics and HIV/AIDS Research Division: Policy Brief. The gendered burden of home-based caregiving. USAID.

http://allafrica.com/sustainable/resources/view/00010373. Accessed on 10/03/2009.

BAKER, S; WILLIAMS, E; JUMA, M AND MAHENDRA, V 2005: Population Council, HIV AND AIDS Stigma and Discrimination. http:// www.popcouncil.org/hivaids/ stigma.html. Accessed 06 April 2005.

BENNET, L; ROSS, MW \& SUNDERLAND, $R$ 1996: The relationship between recognition, rewards and burnout in AIDS caring. AIDS care. Journals Oxford 8(2): 145-153.

BURNS, NAND GROVE, S 2007: The practice of nursing research. USA: W.B. Saunders.

CRESWELL, JW 2009: Research design. Qualitative, Quantitave and Mixed Methods approaches. Thousand Oaks, California: Sage.

DE VOS, AS; STRYDOM, H; FOUCHÉ, CB \& DELPORT, CSL 2007: Research at Grass Roots. For the social sciences and human service pro- 
fessions. Pretoria:Van Schaik.

HENNING, E; VAN RENSBURG, W \& SMIT B 2004: Finding your way in qualitative research. Pretoria: Van Schaik.

LEAKE, M 2009: HIV and AIDS care in the home. AVERT. http// www.avert.org/aids-home-care.htm. Accessed 11/03/2009.

LOBIONDO-WOOD, G \& HABER, J 2002: Nursing Research. Methods, Critical Appraisal and Utilization. Philadelphia: Mosby

LINDSEY, E; HIRSCHFELD, M; TLOU, $S \&$ NCUBE, E 2003: HomeBased care in Botswana: Experiences of older women and young girls. $\underline{\text { Health }}$ Care for Women International. (24):486501.

MAISTER, N. 2001: AIDS Law project and AIDS Legal network.

MORSE, JM; SWANSON, JM \& KUZEL, AJ 2001: The nature of qualitative evidence. London: Sage.

NEUMAN, WL 2000: Social research methods. Qualitative and quantitative approaches. London: Allyn \& Bacon.

PELTZER, K; SKINNER, D; MFECANE, S; SHISANA, O; NQEKETO, A \& MOSALA, T 2005: Factors influencing the utilization of prevention of mother-to-child-transmission (PMTCT) services by pregnant women in the Eastern Cape, South Africa. Health SA. Accredited Interdisciplinary Research Journal. 10 (1):26-39.

PHALADZE, NA. (n.d.): 1st SADC Conference on Community Homebased Care. The plight of family caregivers in Home-based Care in Botswana. Health and Development Networks.

PISTORIUS, AG 2002: Action learning and reflection with HIV and AIDS home-based care workers in Gauteng. Voluntary HIV/AIDS home-based care work traps $=$ A predatory health care system? ( $8^{\text {th }}$ Annual Qualitative methods conference, 1 May 2002)

RUBIN, HJ \& RUBIN, IS 2005: Quali- tative Interviewing. The art of Hearing Data. London: Sage.

SEBANYONI-MOTHLASEDI, M 2003: Stigma and access to care. Nursing update. 27(10): 32-33. Pretoria: DENOSA.

SMITH, JE 2003: Home Health CareSolving the problem. Nursing update. 27 (6): 28-34. Pretoria: DENOSA.

SOUTH AFRICA (REPUBLIC) 2007: HIV/AIDS/STD Strategic plan for South Africa 2007-2011. Department of Health, Pretoria: Government Printer.

SOUTHAFRICA (REPUBLIC) 2001: Comprehensive home/community based care training manual. Department of Health, Pretoria: Government Printer.

SOUTH AFRICA (REPUBLIC) 2001: National Guideline on home-base care / community-based care. Department of health, Pretoria: Government Printer.

USAID. 2004: Big Issues. Scaling up responses to HIV/AIDS. Stigma and HIV/AIDS - A pervasive issue. USA: Synergy.

UYS, L \& CAMERON, S 2003: Homebased HIV and AIDS care. Oxford: University Press. 